\title{
Declining trends in risk behaviors and HIV/ STIs among Clients of FSWs in India: findings from large scale bio-behavioral surveys from three high prevalent Southern states
}

\author{
Article by Lakshmi Ramakrishnan ${ }^{1}$, Shreena Ramanathan ${ }^{1}$, Thilakavathi \\ Subramanian $^{2}$, Diwakar Yadaw ${ }^{1}$, Prabuddhagopal Goswami ${ }^{3}$, Rajatashuvra \\ Adhikary $^{3}$, Venkaiah $\mathrm{K}^{4}$, Bitra George ${ }^{1}$, R.S. Paranjape ${ }^{5}$ \\ ${ }^{1}$ FHI 360, New Delhi, India \\ ${ }^{2}$ National Institute of Epidemiology (NIE), Chennai \\ ${ }^{3}$ FHI 360, Washington DC \\ ${ }^{4}$ National Institute for Nutrition (NIN), Hyderabad \\ ${ }^{5}$ National AIDS Research Institute (NARI), Pune \\ Email: bgeorge@fhi360.org
}

\begin{abstract}
Introduction

There is increasing recognition of the importance of clients of FSW as bridge group to HIV transmission. However, there is paucity of evidence that establishes the HIV vulnerabilities or risk among clients in India. The current analysis examines the changes in risk behaviors (condom use), prevalence of HIV and STIs, and the factors associated with condom use behaviors among clients of sex workers in three Indian states using data from a large scale cross-sectional bio-behavioural survey.

Methods

Data were derived from two rounds of integrated behavioural and biological assessments (IBBA) conducted among clients in the years 2006 and 2009 in Andhra Pradesh, Tamil Nadu and Maharashtra, India. Eligible clients for the survey included men aged 18 years or older who had bought sex from a FSW at least once in the previous month.Two stage probability sampling was used and time location clusters sampling was applied. Consented participants completed structured interviews to collect behavioural data and provided blood and urine samples for HIV, Neisseria gonorrhea, Chlamydia trachomatis, and syphilis testing.

Results

Samples of 4,821 and 4,803 clients were covered in IBBA rounds 1 and 2, respectively. The majority of the clients were literate, ever married and worked as a laborer in two consecutive rounds. Over three fourth of clients had first paid sex before age 25 years. Clients of FSWs had a higher level of condom use during last sex act (AOR-2.5, 95\% CI 1.9-3.3) and consistent condom use (AOR-3.1, 95\% CI-2.1-3.9) with occasional FSWs during Round 2, compared with Round 1. Clients 24 years or younger (AOR=4.2; 95\% CI: 2.9-6.2) were most likely to have reported consistent condom use with FSWs when compared with clients 40 years or older. Clients who reported having sex with other men, were less likely to report consistent condom use (AOR=0.63; 95\% CI: 0.4-0.8) with FSWs. Clients who had exposure to messages on STIs or condom use through media advertising were significantly more likely to report consistent condom use with FSWs (AOR=1.6; 95\% CI: 1.1-2.3). Logistic regression analysis of factors associated with having an STI indicates that clients having sex with another man have significantly higher likely hood of having an STI (9.1\% versus $6.6 \%$; $A O R=1.8$; 95\% CI: $1.1-2.9$ ).

\section{Conclusion}

The findings strongly suggest improvements in condom use among the bridge population, which is also confirmed by the non-increase in HIV and STI prevalence. Exposure to media messages on STIs and condom have shown to positively influence condom use. These findings have programmatic implications, in that it increases understanding about the sub-populations
\end{abstract}


South American Journal of Public Health

Special Edition May 2016

of bridge populations more at risk and who need to be reached with more tailored interventions.

\section{Background}

It has been well established that the HIV epidemic is India is driven largely through heterosexual transmission ${ }^{1}$ and driven by bridge populations through transactional sex with female sex workers (FSWs) ${ }^{2-4}$. Clients of FSWs therefore are a very important bridge group in the transmission of HIV / AIDS. Studies among clients of sex workers are limited and show that clients are at a greater risk of acquiring HIV and STIs. Available studies suggest that clients of sex workers are most likely to be married, illiterate, in the age group of 25-35 years, are laborers or transport workers and consume alcohol ${ }^{5,6}$. Recent studies from India ${ }^{7}$ have suggested that purchase of sex from female sex workers is prevalent in higher prevalence Indian states, and the rate of unprotected sexual contact between clients and FSWs in addition to the size of FSW populations have been found to be the key driver of HIV in India and other Asian countries ${ }^{8}$.

There is increasing recognition [national program] of the importance of clients of FSW as bridge group to HIV transmission / epidemic in India and a number of prevention efforts have targeted male clients across the country. The focus of the prevention interventions is condom social marketing, STI and HIV testing and provision of treatment and care services.

Previous studies from India have examined the prevalence of risk behaviors and estimated size of clients ${ }^{6,7}$. However few studies in the Indian context have examined the changes in sexual risk over time, factors associated with sexual risk taking among bridge groups and effect of prevention interventions on risk behaviors among Clients of FSWs. As part of the Bill \& Melinda Gates funded Avahan, India AIDS initiative, two rounds of bio-behaivoral surveys termed Integrated Behavioral and Biological Assessments (IBBA) were conducted, which included sample of clients of FSW in the three high prevalent southern states: Andhra Pradesh, Maharashtra and Tamil Nadu. The current paper presents the key findings from analysis of data on clients of FSW from these two rounds. The main objectives were to assess changes in risk behaviors (condom use), prevalence of HIV and STIs, and the factors associated with condom use behaviors, including exposure to interventions.

\section{Methodology}

\section{Data Source}

Data for the present analysis was taken from two rounds of IBBA conducted in 2005-07 and in 2009-10 where 4821 and 4803 clients of FSWs were sampled respectively. Twelve districts from three states, Andhra Pradesh, Tamil Nadu, and Maharashtra were chosen purposively based on representation of socio-cultural region and size of the high risk group population'. Probability based sampling method appropriate for mobile groups, time location cluster sampling was used to sample clients of FSWs at FSW solicitation places in each district $^{6,10}$. Eligible clients for the survey included men aged 18 years or older who had bought sex from a FSW at least once in the previous one month. Complete details of the survey design were discussed in Saidel et al. ${ }^{9}$. Both round of survey collected information on behavioural risk and biological specimen (blood and urine) to test for STI (Neisseria gonorrhea, Chlamydia trachomatis, and syphilis) and HIV.

\section{Analytical framework}

According to the framework by Boerma and Wier ${ }^{11}$, factors affecting risk of HIV transmission could be categorized into underlying and proximate determinants. In the current analysis we planned to examine key proximate determinants among Clients of FSW, condom use and presence of STIs, and the factors associated with improved condom use and having STIs. 


\section{Measures}

Changes in outcome variables between round 1 and round 2 of IBBA were examined. These included condom use, both last time and consistent condom use with different partners of clients of FSWs, and positivity for HIV and STIs.

\section{Types of partners}

Partners of clients included in the analysis were occasional and regular FSWs, main regular female partner (spouse or regular female partner), and other female casual partner (other girl friend or lover). Occasional FSWs was someone whom the client had not had sex with before and not known or recognized by the client, whereas regular FSW was one whom the client visited repeatedly and was known to him.

\section{Condom use with partners}

Condom use variables included last time condom use that is condom use at last sex act with any partner and consistent condom use, defined as, using condom every time when having sex with a partner.

\section{HIV and STIs}

Blood samples were tested for HIV infection with a two-test algorithm using an enzyme immunoassay (J. Mitra, New Delhi) ${ }^{9}$. Blood samples were also tested for syphilis using rapid plasma reagin (RPR) and a confirmatory Treponema pallidum hemagglutination assay (TPHA). Positive RPR confirmation by TPHA was used to define reactive syphilis or lifetime syphilis. RPR titres of $\geq 1: 8$ with a confirmatory TPHA were defined as active or high-titre syphilis. Urine was tested using nucleic-acid amplification (Gen-Probe APTIMA COMBO 2) to assess Chlamydia (CT) and gonococcal (GC) urethral infections ${ }^{9}$. For the analysis, a composite variable 'any STI' was defined as those testing positive for either syphilis, NG or CT.

\section{Statistical Analysis:}

District level data from 12 districts in the three states was first aggregated for each round of IBBA. Data from both rounds of IBBA were then pooled and appropriate weights were calculated and applied in the analysis. Bivariate analysis was first done to examine changes in the key demographic variables between two rounds of IBBA;

Determinants of the two main outcome measures that were examined are: consistent condom use with an FSW, including occasional or regular FSW; and having any STIs. Clients who reported using condoms every time when they had sex with an occasional and/ or a regular FSW were categorized as 'consistent condom users'. Clients of FSW who tested positive for any STI, that is syphilis, gonorrhoea or Chlamydia, were categorized as having an STI.

Multivariate logistic regression analyses were conducted to assess the changes in the key outcomes and the two IBBA rounds, after controlling for confounding, including sociodemographic factors found to be different between the two rounds of IBBA. These included: district, literacy, marital status, age at first paid sex, localite, number of FSWs partners, place of solicitation, and having regular female partner. Background characteristics and other factors that may be related to the outcomes were analyzed against outcome variables to determine any associations. Factors that were significant in the bivariate analysis were then included in multivariate logistic regression where dependent variables were consistent condom use with any FSW (occasional and regular FSW) and having any STI. Significance at the $95 \%$ confidence level was based on $p$-value $<0.05$. All statistical analysis was conducted using SPSS version 15.0. 
South American Journal of Public Health

Special Edition May 2016

\section{Ethical Review}

Ethical review and Institutional Review Board approvals for both round of IBBA was sought and received from FHI 360's Protection of Human Subjects Committee (PHSC) and the Health Ministry Screening Committee (HMSC) of the Indian Council of Medical Research (ICMR) institutions. State level ethical reviews and approvals were also obtained from the different ICMR institutes that implemented the study in each state?

\section{Results:}

Data from 9624 clients of FSWs from 12 districts of Andhra Pradesh, Tamil Nadu and Maharashtra were analyzed.

Table 1 shows the percent distribution of the clients of FSWs by round- 1 and round-2, according to socio-economic, behavioural and biological characteristics. The mean age of clients of FSWs was 29 yearsin both rounds of IBBA. The majority of the clients were literate, ever married and worked as a labourer in two consecutive rounds. Over three fourth of clients had first paid sex before age 25 years. More than 55 percent of the clients usually solicited in brothel or lodge or home across the two surveys. Consistent condom use with regular and occasional FSWs significantly increased over the period in 2005 (Round 1) -2009 (Round 2). Biological indicators including HIV-1 infection, syphilis, Chlamydia infection, Gonorrhoea infection did not change significantly between 2005 and 2009.

Table 2 presents crude and adjusted odds ratio of risky sexual behaviour and biological indicators of clients of FSWs by IBBA round. In multivariate analysis, clients of FSWs had a higher level of condom use during last sex act (AOR-2.5, 95\% CI 1.9-3.3) and consistent condom use (AOR-3.1, 95\% CI-2.1-3.9) with occasional FSWs during Round 2, compared with Round 1. Condom use at last sex act with regular FSWs was not significantly different between round 1 and round 2; however clients of FSWs in Round 2 had significant higher likely-hood of using condoms consistently with regular FSWs (AOR-2.6, 95\% CI-2.0-3.5). There were no significant differences in consistent condom use with main regular female partner, and condom use at last sex act with other casual partners between Round 1 and Round 2.

HIV prevalence did not change between Round 1 (6.8\%) and Round 2 (6.7\%) similarly no difference was observed in prevalence of lifetime syphilis between Round 1 (4.7\%) and Round (4\%) of survey. Prevalence of Chlamydia and Gonorrhoea was low and did not change between two rounds.

Table 3 presents results from logistic regression analysis of factors associated with consistent condom use with both occasional and regular FSWs. Crude and Adjusted Odds Ratio (AOR) by selected background characteristics of clients are presented. Age, MSM activity and exposure to media interventions were found associated with consistent condom use. Younger age was associated with consistent condom use; and clients 24 years or younger (AOR=4.2; 95\% CI: 2.9-6.2; $\mathrm{p}=0.00$ ) were most likely to have reported consistent condom use with FSWs when compared with clients 40 years or older. Clients who reported having sex with other men, were less likely to report consistent condom use (AOR $=0.63 ; 95 \%$ CI: 0.4-0.8; $\mathrm{p}=0.004$ ) with FSWs. Clients who had exposure to messages on STIs or condom use through media advertising were significantly more likely to report consistent condom use with FSWs (AOR=1.6; 95\% CI: 1.1-2.3; $\mathrm{p}=0.018)$.

Logistic regression analysis of factors associated with having an STI indicate that clients having sex with another man have significantly higher likely hood of having an STI $19.1 \%$ versus $6.6 \%$; $\mathrm{AOR}=1.8 ; 95 \% \mathrm{CI}: 1.1-2.9 ; \mathrm{p}=0.019$ ). No other variables were found to be associated with having STI. 


\section{Discussion}

While the role of bridge populations in the transmission of HIV and STI is well acknowledged, bridge populations are difficult to study and few research studies are available. IBBA is one of the few studies among clients of FSW that provide robust estimates of risk behaviors and determinants of HIV risk. Our analysis based on large cross-sectional surveys among clients of FSW in southern India has found that, there has been significant increase in HIV preventive behavior (consistent condom use) with commercial sexual partners and no change in HIV and STI prevalence between 2006 and 2009. The analysis also suggests that media based interventions have significantly contributed to the increase in condom use. The evidence from the analysis indicates that younger age and having regular female partner are strong determinants of consistent condom use with commercial partners; and men who indulge in sex with other men have are less likely to use condoms with FSW and have higher risk of STIs.

Profile of clients in the current study was that a majority of clients were married and having regular female partner; this also increased significantly over time. Similar results have been reported from behavioral surveillance survey among clients in India, where over half the clients were married ${ }^{7}$. Age structure of clients found in this study is similar to the that of clients captured in the National behavioral surveillance ${ }^{12}$ and other studies from social marketing programs of clients in India ${ }^{13}$. Other behavioural studies among clients in another southern state in India reported similar profile of clients as in the current study, with average age being 30 years and over $60 \%$ of clients being married ${ }^{13,14}$.

Patterns of sexual risk taking among clients are likely to influence the risk of HIV and STIs. Our analysis indicates that in the states examined, age at sexual debut and age at paid sex with FSW occur early, before 19 and through 24 years. The study by Gaffey et al, reports that in the Indian states with high HIV, having sex with FSW was most prevalent among clients between ages 15 to 24 years $^{7}$. Combined with the results from our analysis this suggests the programmatic strategies need to include reaching young men with messaging on safe sex practices and risks of HIV and STIs.

Another sexual risk behavior found to have increased over time was the reported prevalence of sex with male partners. Given the published reports on the risks of HIV transmission among bisexual men ${ }^{15,16}$ and as clients who report sex concurrently with FSW and male partners, there is a potential to act as bridge between the two different sexual networks, and therefore further studies and analysis of subgroup of clients engaging in sex with males is critical.

One the key findings from our analysis are a significant increase (over 50\%) in consistent condom use during commercial sexual encounters, including with occasional and regular FSWs. Given that there is no increase in any of the biological estimates (HIV and STI) add to the plausibility of improved safe sex practices with commercial partners. However this is lower than reports from other studies, such as $72 \%$ by Gaffey et al and $80 \%$ or more reported by Lipovsek et $\mathrm{al}^{13}$. The definition of consistent condom used by Lipovsek was different (composite variable of last and consistent condom use in last 12 months) and therefore not directly comparable to our results. The findings from IBBA surveys among FSWs in the same three southern states as the current study have reported $90 \%$ or higher prevalence of consistent condom use with any type of clients ${ }^{1718}$. It is possible that FSWs have higher levels of social desirability bias to report consistent condom use, compared with clients of FSWs, given the long duration and high reach of interventions for core risk groups in the southern states of India ${ }^{6,19,20}$. Needless to say, consistent condom use by clients of FSW needs to be a prioritized measure for programmatic interventions. This coupled with the nearly non-existent use of condoms with regular female partners, will contribute to vertical transmission of HIV and STI and spread to the general population.

Few studies have examined the determinants of condom use among clients of FSW and this is a key contribution from the current analysis. Young age was significant determinant for consistent condom use after controlling for confounding factors; a dose response type of 
increase in adjusted ORs from older to younger clients indicates the strength of the association between younger age and consistent condom use.

As found earlier this indicates that older clients are more at risk and need to be focused upon by interventions ${ }^{6}$. Exposure to media based communication on STIs and condom use was found to be a significantly associated with condom use; the studies by Lipovskey ${ }^{13}$, Suryawanshi ${ }^{21}$ that evaluated condom use among clients who were exposed to media interventions reported condom use. A meta-analysis of the effect of social marketing efforts on condom use ${ }^{22}$ also found increased likely hood of condom use; the interventions for clients of FSWs in the states sampled in IBBA were a combination of social marketing of condoms and media based campaigns ${ }^{13,23}$; given the rigorous methodology of IBBA, the findings from the current analysis add to the evidence base for the efficacy of social marketing efforts.

The finding that clients having a regular female partner are more likely to use condoms consistently, suggest that programmatic interventions have been effective in facilitating behavior change. These programmatic strategies may be further strengthened through profiling, so that risk among all ages of clients can be addressed.

The limitations of the current study are that non -cooperation rates averaged at about $30 \%$. While it was not quantified, the main reasons for refusal was that clients were not available to participate, or in some cases not wanting to be identified as a client of FSW. Higher participation rates have been reported by other studies on clients of FSWs ${ }^{24-26}$, however these studies sampled clients from fixed venues or after taking prior permission from gate-keepers such as pimps or with support of the FSWs. As described earlier, clients in IBBA were recruited randomly from places where they pick up FSWs, (predominantly public places and some home and brothels) ${ }^{6,9}$, and including only those who bought sex in the last one month, increasing the likely hood of capturing clients who are more frequent purchasers of sex and a sub-group of high risk clients. The age structure of clients in IBBA is similar to that of clients captured in other National studies (National BSS), so it can be safe to assume that this sample is sufficiently representative of clients in India.

\section{Conclusion}

The current study findings are a vital source of data on risk behaviors and biological estimates from India on bridge population that is clients of FSWs, who are hard to reach both by programs as well as research studies. The most important findings from the study are that there is improved condom use (reduced sexual risk taking) among bridge population which is confirmed by the non-increase in HIV and STI prevalence between the two rounds of studies. The findings strongly suggest improvements in condom use among this group, which is a proxy for the general population, which suggests that HIV prevention efforts in the southern states studied, have made a significant contribution. The findings have programmatic implications, in that it increases understanding about the sub-populations of bridge populations more at risk and who need to be reached with more tailored interventions. The findings from our study add to the existing body of literature on reach and effects of social marketing and media based behavior communication methods and about their potential effectiveness for decreasing HIV risk behaviors on general populations. These data can further contribute to the informing HIV prevention programs among core risk and bridge groups, and for modeling the vertical transmission of HIV to general populations.

\section{Acknowledgements}

The authors wish to thank Avahan's state implementation partners for their alliance in implementing this study.

\section{Competing interests}

The authors have declared that no competing interests exist. 


\section{Disclaimer}

Support for this study was provided by the Bill \& Melinda Gates Foundation through Avahan, its India AIDS initiative. The views expressed herein are those of the authors and do not necessarily reflect the official policy or position of the Bill \& Melinda Gates Foundation or Avahan.

\section{Changes in Profile, risk behaviors and HIV/ STI prevalence among clients of FSWs}

Table 1: Socio-demographic characteristics of clients of female sex workers of IBBA in round-I and round-II (Aggregate level for AP, TN and MH

\begin{tabular}{|c|c|c|c|}
\hline Variables & $\begin{array}{c}\text { Round-I } \\
\%(\mathrm{n}=4821)\end{array}$ & $\begin{array}{c}\text { Round-II } \\
\%(\mathrm{n}=4803)\end{array}$ & $\begin{array}{c}\text { P value } \\
\text { (Wald-Pearson) }\end{array}$ \\
\hline \multicolumn{4}{|l|}{ Socio-demographic factors } \\
\hline \multicolumn{4}{|l|}{ Current age (years) } \\
\hline$<=24$ & 32.4 & 28.0 & \multirow{5}{*}{0.332} \\
\hline $25-29$ & 22.7 & 25.1 & \\
\hline $30-39$ & 29.2 & 30.5 & \\
\hline $40+$ & 15.7 & 16.4 & \\
\hline Mean & 29.2 & 29.7 & \\
\hline \multicolumn{4}{|l|}{ Literacy } \\
\hline Literate & 77.1 & 71.8 & 0.033 \\
\hline \multicolumn{4}{|l|}{ Marital status } \\
\hline Not currently married & 46.7 & 38.4 & \multirow{2}{*}{0.002} \\
\hline Currently married & 53.3 & 61.6 & \\
\hline \multicolumn{4}{|l|}{ Main Occupation } \\
\hline Unemployed & 3.5 & 1.6 & \multirow{4}{*}{0.000} \\
\hline Student / Domestic servant & 14.6 & 7.0 & \\
\hline Labour/Business/Service & 70.1 & 77.9 & \\
\hline Transport workers & 11.9 & 13.5 & \\
\hline \multicolumn{4}{|l|}{ Sexual behavior factors } \\
\hline \multicolumn{4}{|l|}{ Age at first sex (Years) } \\
\hline$<19$ & 46.4 & 46.5 & \multirow{2}{*}{0.474} \\
\hline $19+$ & 53.6 & 53.5 & \\
\hline \multicolumn{4}{|l|}{ Age at first paid sex (Years) } \\
\hline$<20$ Years & 41.8 & 35.1 & \multirow{4}{*}{0.000} \\
\hline 20-24 Years & 46.8 & 42.2 & \\
\hline 25-29 Years & 8.0 & 11.8 & \\
\hline $30+$ Years & 3.4 & 7.1 & \\
\hline \multicolumn{4}{|l|}{ Duration of buying sex } \\
\hline$<=1$ year & 11.9 & 9.5 & \multirow{4}{*}{0.099} \\
\hline $2-3$ years & 17.3 & 18.4 & \\
\hline 4-9 years & 31.2 & 32.7 & \\
\hline $10+$ years & 39.3 & 39.1 & \\
\hline \multicolumn{4}{|l|}{ Residency } \\
\hline Localite & 74.6 & 85.3 & 0.000 \\
\hline \multicolumn{4}{|c|}{ Number of FSWs had sex with in last one month } \\
\hline $1-2$ FSWs & 73.5 & 81.5 & \multirow{3}{*}{0.000} \\
\hline 3-4 FSWs & 18.5 & 14.4 & \\
\hline $5+\mathrm{FSWs}$ & 8.0 & 4.1 & \\
\hline $\begin{array}{l}\text { Number of sex acts with FSWs } \\
\text { month }\end{array}$ & & & \\
\hline
\end{tabular}


South American Journal of Public Health

Special Edition May 2016

\begin{tabular}{llll}
\hline No sex acts & 0.5 & 0.0 & \\
1-3 FSWs & 63.1 & 66.8 & 0.032 \\
4-6 FSWs & 27.2 & 24.1 & \\
7+ FSWs & 8.5 & 8.9 & \\
\hline Place of Solicitation & & & \\
Brothel/Lodge & 20.9 & 15.2 & 0.000 \\
Public Place & 31.0 & 37.7 & \\
Others & 48.1 & 47.1 & 0.017 \\
\hline Partner types and condom use behaviors & & & 0.000 \\
\hline Had regular main/steady partner & 61.2 & 67.2 & 0.000 \\
Had sex with a male/ hijra partner & 9.0 & 16.1 & 0.000 \\
Last time condom use with occasional FSW & 75.2 & 87.4 & 0.021 \\
Consistent Condom use with occasional FSW & 31.9 & 54.6 & 0.000 \\
Last time condom use with regular FSW & 70.1 & 77.0 & 0.003 \\
Consistent condom use with regular FSW & 25.1 & 46.3 & 0.414 \\
Consistent condom use with main female partner & 5.5 & 2.2 & \\
Condom use last sex act with casual partner & 48.4 & 43.3 & 0.926 \\
Biological tests & & & 0.507 \\
\hline HIV-1 infection & 6.8 & 6.7 & 0.103 \\
Syphilis & 4.7 & 4.0 & 0.832 \\
Syphilis high titer & 1.3 & 0.8 & 0.703 \\
Chlamydia infection & 2.4 & 2.8 & 0.832 \\
Gonorrhoea infection & 0.4 & 0.3 & \\
Chlamydia and/or Gonorrhoea infection & 2.8 & 3.0 & \\
\hline
\end{tabular}


South American Journal of Public Health Special Edition May 2016

Table 2. Multivariate analysis for risky sexual behavior of clients of FSWs in India

\begin{tabular}{|c|c|c|c|c|c|c|c|c|c|c|c|c|}
\hline & $\begin{array}{l}\text { Condom } \\
\text { use last } \\
\text { sex act } \\
\text { with } \\
\text { occasional } \\
\text { FSW }\end{array}$ & $\begin{array}{l}\text { Consiste } \\
\text { nt } \\
\text { Condom } \\
\text { use with } \\
\text { occasion } \\
\text { al FSW }\end{array}$ & $\begin{array}{l}\text { Condom } \\
\text { use last } \\
\text { sex act } \\
\text { with } \\
\text { regular } \\
\text { FSW }\end{array}$ & $\begin{array}{l}\text { Consisten } \\
\text { t condom } \\
\text { use with } \\
\text { regular } \\
\text { FSW }\end{array}$ & $\begin{array}{l}\text { Consiste } \\
\text { nt } \\
\text { condom } \\
\text { use with } \\
\text { main } \\
\text { regular } \\
\text { female } \\
\text { partner }\end{array}$ & $\begin{array}{l}\text { Condom } \\
\text { use last } \\
\text { sex act } \\
\text { with } \\
\text { other } \\
\text { casual } \\
\text { partner }\end{array}$ & $\begin{array}{l}\text { HIV-1 } \\
\text { infection }\end{array}$ & Syphilis & $\begin{array}{l}\text { Syphilis } \\
\text { high titer }\end{array}$ & $\begin{array}{l}\text { Chlamyd } \\
\text { ia } \\
\text { infection }\end{array}$ & $\begin{array}{l}\text { Gonorr } \\
\text { hoea } \\
\text { infectio } \\
\text { n }\end{array}$ & $\begin{array}{l}\text { Chlam } \\
\text { ydia } \\
\text { and/or } \\
\text { Gonorr } \\
\text { hoea } \\
\text { infectio } \\
\mathrm{n}\end{array}$ \\
\hline $\begin{array}{l}\text { COR } \\
\text { IBBA } \\
\text { Round 1 }\end{array}$ & B & & & & & & & & & & & \\
\hline Round 2 & $\begin{array}{l}3.025^{* *} \\
(2.629- \\
3.480)\end{array}$ & $\begin{array}{c}2.567 * * \\
(2.052- \\
3.211)\end{array}$ & $\begin{array}{c}1.432 * \\
(1.056- \\
1.942) \\
\end{array}$ & $\begin{array}{c}2.568 * * \\
(1.963- \\
3.360) \\
\end{array}$ & $\begin{array}{c}0.393 * * \\
(0.206- \\
0.748) \\
\end{array}$ & $\begin{array}{c}0.813 \\
(0.495- \\
1.336) \\
\end{array}$ & $\begin{array}{c}0.981 \\
(0.655- \\
1.469) \\
\end{array}$ & $\begin{array}{c}0.841 \\
(0.504- \\
1.403) \\
\end{array}$ & $\begin{array}{c}0.622 \\
(0.350- \\
1.107) \\
\end{array}$ & $\begin{array}{c}1.147 \\
(0.322- \\
4.087)\end{array}$ & $\begin{array}{c}0.788 \\
(0.232- \\
2.682)\end{array}$ & $\begin{array}{c}1.095 \\
(0.336- \\
3.564)\end{array}$ \\
\hline \multicolumn{12}{|l|}{ AOR } & \\
\hline Round 2 & $\begin{array}{c}2.526 * * * \\
(1.934- \\
3.300)\end{array}$ & $\begin{array}{c}3.144 * * * \\
(2.512- \\
3.934) \\
\end{array}$ & $\begin{array}{c}1.424 * \\
(1.024- \\
1.980) \\
\end{array}$ & $\begin{array}{c}2.684 * * * \\
(2.039- \\
3.534) \\
\end{array}$ & $\begin{array}{c}0.869 \\
(0.407- \\
1.859)\end{array}$ & $\begin{array}{c}0.962 \\
(0.581- \\
1.592)\end{array}$ & $\begin{array}{c}0.907 \\
(0.598- \\
1.376)\end{array}$ & $\begin{array}{c}0.794 \\
(0.463- \\
1.362)\end{array}$ & $\begin{array}{c}0.555 \\
(0.298- \\
1.035) \\
\end{array}$ & $\begin{array}{c}0.71 \\
(0.332- \\
1.520)\end{array}$ & $\begin{array}{c}0.371 \\
(0.072- \\
1.926)\end{array}$ & $\begin{array}{c}0.656 \\
(0.320- \\
1.345)\end{array}$ \\
\hline
\end{tabular}

COR-crude odds ratio; AOR-Adjusted odds ratio

$* * *<0.001, * *<0.01, *<0.05$. Multivariate models were adjusted for the following variables: District, Literacy, Marital Status, Age at fist paid sex, Localite, Number of FSW partners, place of solicitation and had regular main/steady partner 
South American Journal of Public Health

Special Edition May 2016

Table-3 Factors of consistent condom use with FSWs (both occasional and regular), India

\begin{tabular}{|c|c|c|c|c|}
\hline \multirow[t]{2}{*}{ Background characteristics } & \multicolumn{4}{|c|}{ India } \\
\hline & $\%$ & AOR & CI & Significance \\
\hline \multicolumn{5}{|l|}{ Current age(in years) } \\
\hline$\leq 24$ & 40.9 & 4.175 & $2.840-6.140$ & \\
\hline $25-29$ & 26.7 & 2.980 & $2.057-4.316$ & \\
\hline $30-39$ & 23.8 & 1.783 & $1.291-2.463$ & 0.000 \\
\hline 40 and above (Ref.) & 8.6 & 1.000 & & \\
\hline \multicolumn{5}{|l|}{ Literacy } \\
\hline Literate & 76.6 & 1.000 & & \\
\hline Illiterate (Ref.) & 23.4 & 0.914 & $0.733-1.141$ & 0.428 \\
\hline \multicolumn{5}{|l|}{ Marital status } \\
\hline Not currently married (Ref.) & 50.3 & 1.000 & & \\
\hline Currently married & 49.7 & 1.171 & $0.845-1.623$ & 0.343 \\
\hline \multicolumn{5}{|l|}{ Main occupation } \\
\hline Unemployed (Ref.) & 2.9 & 1.000 & & \\
\hline Student/Domestic servants & 13.1 & 1.163 & $0.626-2.161$ & \\
\hline Labour/ Businessman/ Services & 72.9 & 0.977 & $0.566-1.718$ & \\
\hline Transport workers & 11.1 & 0.831 & $0.442-1.565$ & 0.432 \\
\hline \multicolumn{5}{|c|}{ Had main regular female partner } \\
\hline Yes & 56.9 & 1.336 & $1.012-1.763$ & 0.041 \\
\hline No & 43.1 & 1.000 & & \\
\hline \multicolumn{5}{|c|}{$\begin{array}{l}\text { Number of FSWs had sex with in } \\
\text { the past month }\end{array}$} \\
\hline $1-2$ (Ref.) & 78.3 & 1.000 & & \\
\hline $3-4$ & 16.8 & 1.034 & $0.808-1.323$ & \\
\hline 5 or more & 4.9 & 0.760 & $0.530-1.089$ & 0.300 \\
\hline \multicolumn{5}{|l|}{ Place of Solicitation } \\
\hline Brothel/Lodge/Home (Ref.) & 49.0 & 1.000 & & \\
\hline Public places & 30.8 & 1.260 & $0.913-1.738$ & \\
\hline Others & 20.2 & 0.899 & $0.724-1.116$ & 0.101 \\
\hline \multicolumn{5}{|l|}{ Had MSM activity } \\
\hline No (Ref.) & 89.0 & 1.000 & & \\
\hline Yes & 11.0 & 0.643 & $0.472-0.875$ & 0.005 \\
\hline \multicolumn{5}{|l|}{$\begin{array}{l}\text { Seen/heard advertisement on } \\
\text { condom/STI/key clinic }\end{array}$} \\
\hline No (Ref.) & 4.1 & 1.000 & & \\
\hline Yes & 95.9 & 1.664 & $1.115-2.483$ & 0.013 \\
\hline
\end{tabular}

Table-4 Factors of any STI among clients of FSW.

\begin{tabular}{lccll}
\hline Background characteristics & & & India & \\
& $\%$ & AOR & CI & p-value \\
\hline Current age(in years) & & & & \\
$\leq 24$ & 5.1 & 0.749 & $0.396-1.417$ & 0.726 \\
$25-29$ & 6.2 & 0.845 & $0.420-1.700$ & \\
$30-39$ & 8.9 & 1.125 & $0.544-2.328$ & \\
40 and above (Ref.) & 7.7 & 1.000 & & \\
$\quad$ Literacy & & & & \\
Literate & 8.8 & 1.000 & &
\end{tabular}




\begin{tabular}{lllll} 
Illiterate (Ref.) & 6.3 & 1.340 & $0.608-2.957$ & 0.468 \\
Marital status & & & & \\
Not currently married (Ref.) & 4.5 & 1.000 & & 0.333 \\
$\begin{array}{l}\text { Currently married } \\
\text { Main occupation }\end{array}$ & 8.4 & 1.324 & $0.750-2.340$ & \\
Unemployed/student (Ref.) & 3.1 & 1.000 & & \\
Student/Domestic servant & 6.4 & 1.395 & $0.503-3.868$ & 0.766 \\
Labour/ Businessman/ Service & 6.8 & 1.420 & $0.552-3.652$ & \\
Transport workers & & 2.083 & $0.523-8.299$ & \\
Number of FSWs had sex with in & & & & \\
the past month & & & & \\
1-2 (Ref.) & 7.5 & 1.000 & & \\
3-4 & 4.2 & 0.542 & $0.291-1.009$ & \\
5+ & 6.2 & 0.759 & $0.413-1.393$ & 0.151 \\
Place of Solicitation & & & & \\
Brothel/Lodge (Ref.) & 7.6 & 1.000 & & \\
Others & 4.0 & 0.491 & $0.268-0.900$ & \\
Public places & 7.4 & 0.893 & $0.472-1.692$ & 0.053 \\
Seen/heard advertisement on & & & & \\
condom/STI/key clinic & & & & \\
No (Ref.) & 9.5 & 1.000 & & \\
Yes & 6.7 & 0.672 & $0.229-1.970$ & 0.468 \\
Had MSM activity & & & & \\
Yes & 9.1 & 1.810 & $1.104-2.969$ & 0.019 \\
No & 6.6 & 1.000 & & \\
\hline
\end{tabular}

\section{References}

[1.] National AIDS Control Organisation MoHFW, Government of India. Annual Report 2006. 2007.

[2.] Kumar R JP, Arora P, Dhingra N, Rao S HIV-1 trends, risk factors and growth in India. 2005.

[3.] Nagelkerke NJD JP, de Vlas SJ, Korenromp EL, Moses S, et al. Modelling HIV/AIDS epidemics in Botswana and India: impact of interventions to prevent transmission. Bull World Health Organ 2002;80(2):89-96.

[4.] Venkataramana CB SP. Extent and speed of spread of HIV infection in India through the commercial sex networks: a perspective. Trop Med Int Health 2001;6(12):1040-1061.

[5.] National AIDS Control Organisation MoHaFW, Government of India. 2006. New DelhiNational Behavioural Surveillance Survey (BSS)-Female Sex Workers (FSWs) and their Clients.

[6.] Subramanian T, Gupte MD, Paranjape RS, et al. HIV, sexually transmitted infections and sexual behaviour of male clients of female sex workers in Andhra Pradesh, Tamil Nadu and Maharashtra, India: results of a cross-sectional survey. AIDS. . 20081222 DCOM- 200902202008 22 ( 5):S69-79. .

[7.] Michelle F. Gaffey SV, Neeraj Dhingra, Ajay Khera, Rajesh Kumar, Paul Arora, Nico Nagelkerke, Prabhat Jha. Male Use of Female Sex Work in India: A Nationally Representative Behavioural Survey. PLOS ONE. 2011;6(7).

[8.] Ruxrungtham K BT, Phanuphak P HIV/AIDS in Asia. Lancet. 2004;364(9428):69-82.

[9.] Saidel T, Adhikary R, Mainkar M, et al. Baseline integrated behavioural and biological assessment among most at-risk populations in six high-prevalence states of India: design and implementation $\begin{array}{llll}\text { challenges. } & \text { AIDS } & \text { (London, } & \text { England). }\end{array}$ 10.1097/1001.aids.0000343761.0000377702.0000343704.

[10.] Saidel T LV, Salyuk T, Emmanuel F, Morineau G, Lyerla R. . Applying current methods in size estimation for high risk groups in the context of concentrated epidemics: Lessons learned. jHASE 2010:1-24. 
South American Journal of Public Health

Special Edition May 2016

[11.] Boerma JT, Weir SS. Integrating demographic and epidemiological approaches to research on HIV/AIDS: the proximate-determinants framework. J Infect Dis. Feb 1 2005;191 Suppl 1:S61-67.

[12.] Organization NAC. Natinal behavioral surveillance survey among general population. 2006.

[13.] Lipovsek V, Mukherjee A, Navin D, Marjara P, Sharma A, Roy KP. Increases in self-reported consistent condom use among male clients of female sex workers following exposure to an integrated behaviour change programme in four states in southern India. Sexually transmitted infections. 2010;86(1):038497.

[14.] Shaw S, Deering K, Reza-Paul S, et al. Prevalence of HIV and sexually transmitted infections among clients of female sex workers in Karnataka, India: a cross-sectional study. BMC public health. 2011;11(Suppl 6):S4.

[15.] Phillips AE, Lowndes CM, Boily MC, et al. Men who have sex with men and women in Bangalore, South India, and potential impact on the HIV epidemic. Sexually Transmitted Infections. June 1, 2010 2010;86(3):187-192.

[16.] Hernandez AL, Lindan CP, Mathur M, et al. Sexual behavior among men who have sex with women, men, and Hijras in Mumbai, India--multiple sexual risks. AIDS Behav. Jul 2006;10(4 Suppl):S5-16.

[17.] Rajatashuvra Adhikary AG, Satya Ranjan Lenka, Prabuddhagopal Goswami, Lakshmi Ramakrishnan, Bitra George, Mandar K. Mainkar, S. Thilakavathi,, Paranjape GNVBRR. Decline in unprotected sex \& sexually transmitted infections (STIs) among female sex workers from repeated behavioural \& biological surveys in three southern States of India. The Indian journal of medical research. 2012;136:5-13.

[18.] Ramesh BM, Moses S, Washington R, et al. Determinants of HIV prevalence among female sex workers in four south Indian states: analysis of cross-sectional surveys in twenty-three districts. AIDS (London, England). 2008;22(5).

[19.] Mainkar M, Pardeshi D, Dale J, et al. Targeted interventions of the Avahan program and their association with intermediate outcomes among female sex workers in Maharashtra, India. BMC public health. 2011;11(Suppl 6):S2.

[20.] Rachakulla HK, Kodavalla V, Rajkumar H, et al. Condom use and prevalence of syphilis and HIV among female sex workers in Andhra Pradesh, India - following a large-scale HIV prevention intervention. BMC public health. 2011;11(Suppl 6):S1.

[21.] Suryawanshi D, Bhatnagar T, Deshpande S, Zhou W, Singh P, Collumbien M. Diversity among Clients of Female Sex Workers in India: Comparing Risk Profiles and Intervention Impact by Site of Solicitation. Implications for the Vulnerability of Less Visible Female Sex Workers. PloS one. 2013;8(9):e73470.

[22.] Michael D Sweat JD, Caitlin Kennedy, Virginia Tedrow \& Kevin O'Reilly Effects of condom social marketing on condom use in developing countries: a systematic review and meta-analysis, 19902010. Bulletin of the World Health Organization 2012;90:613-622A.

[23.] Piot B, Mukherjee A, Navin D, et al. Lot quality assurance sampling for monitoring coverage and quality of a targeted condom social marketing programme in traditional and non-traditional outlets in India. Sexually transmitted infections. February 1, 2010 2010;86(Suppl 1):i56-i61.

[24.] Gomes do Espirito Santo ME, Etheredge GD. Male clients of brothel prostitutes as a bridge for HIV infection between high risk and low risk groups of women in Senegal. Sexually transmitted infections. 2005;81(4):342-344.

[25.] Vuylsteke BL, Ghys PD, Traore M, et al. HIV prevalence and risk behavior among clients of female sex workers in Abidjan, Cote d'Ivoire. AIDS (London, England). 2003;17(11):1691-1694.

[26.] Espirito Santo ME, Etheredge GD. How to reach clients of female sex workers: a survey by surprise in brothels in Dakar, Senegal. Bull World Health Organ. 2002;80(9):709-713. 